\title{
Partitioning and sources of PAHs in wastewater receiving streams of Tianjin, China
}

\author{
Weixiao Qi • Jiuhui Qu • Huijuan Liu • \\ Chengzhi Hu • Huachun Lan · \\ Huimin Ren • Wei Xu
}

Received: 24 November 2010 / Accepted: 11 April 2011 / Published online: 5 May 2011

(C) Springer Science+Business Media B.V. 2011

\begin{abstract}
Polycyclic aromatic hydrocarbons (PAHs) partitioning among dissolved phase, suspended particulate matter, pore water, and sediment was studied in one moderately contaminated river (Yongding New River) and two highly contaminated drainage canals (South Drainage Canal and North Drainage Canal) of Tianjin, China. PAHs concentrations in sediment (ranged from 0.2 to $195 \mu \mathrm{g} / \mathrm{g}$ ) showed positive relations with both total organic carbon contents (ranged from $0.7 \%$ to $31.1 \%$, dw) and black carbon contents (ranged from $0.1 \%$ to $2.1 \%, \mathrm{dw}$ ) in the sediments. Moreover, most of the measured organic carbon normalized partition coefficients of PAHs in the three streams were 0.76 to 1.54 log units higher than the predicted values. These indicated that strong and nonlinear sorption
\end{abstract}

W. Qi · J. Qu ( $\varangle)$ · H. Liu · C. Hu · H. Lan ·

H. Ren · W. Xu

State Key Laboratory of Environmental Aquatic

Chemistry, Research Center for Eco-Environmental

Sciences, Chinese Academy of Sciences,

Beijing 100085, China

e-mail: jhqu@rcees.ac.cn

W. Qi · W. Xu

Graduate School, Chinese Academy of Sciences,

Beijing 100039, China of PAHs by carbonaceous geosorbents such as black carbon (BC) existed in the streams, and $\mathrm{BC}$ was an important part of the carbonaceous particles controlling the partitioning of PAHs in the sediments of this study. PAH component ratio analyses suggested that PAHs in the three streams, effluent samples from wastewater treatment plants, and soil samples by the riverbank had similar main sources, which is coal/petroleum combustion. We suggested the transportation and transformation of both carbonaceous particles and PAHs during wastewater treatment process, surface runoff, etc, should be studied further in order to make decisions on PAHs controlling measures.

Keywords PAHs • Partition - Organic matter • Black carbon $\cdot$ Component ratio

\section{Introduction}

Polycyclic aromatic hydrocarbons (PAHs) enter rivers and estuaries by direct wastewater discharges, riverine inflow and atmospheric deposition. They then become subject to distribution and accumulation among the water column, suspended particulate matter, bottom sediments, and biota. It is well-known that dissolved organic matter in water as well as organic material in 
suspended particulate matter (SPM) and sediment are important vectors for PAH's partition and behavior among various phases in the rivers.

In the early 1990s, Weber et al. (1992) hypothesized that organic matter consisted of a heterogeneous mix of sorbents, for example, "soft" and "hard" carbon. Researchers observed that heterogeneity in naturally occurring carbonaceous materials (CMs) caused sorption processes of hydrophobic organic compounds (HOCs) in sediments to occur as a combination of absorption into amorphous organic matter and adsorption onto condensed forms of CMs such as black carbon (BC), coal, and kerogen, collectively termed "carbonaceous geosorbents" (CG) (Allen-King et al. 2002; Cornelissen et al. 2005). Many studies reported that adsorption of PAHs onto CG can greatly affect their bioavailability and toxicity as "sequestration" of PAHs in sediments often takes place (Gustafsson et al. 1997; Luthy et al. 1997; Nam et al. 1998; Rockne et al. 2002; Shor et al. 2003; Abu and Steve 2005).

High PAHs levels have been reported in streams of Tianjin previously (Qi et al. 2010a, b) as well as other organic pollutants (Shi et al. 2005; Yang et al. 2005; Shao et al. 2005). Investigation of the partitioning and sources of pollutants would lead to a better understanding of risk. However, previous reports regarding the partitioning of these pollutants in different phases are not widely available because of the extremely complex matrix in this area. We focus on Yongding New River which acts as both a water resource for agriculture irrigation and a waterway for flood control in wet seasons and two drainage canals, South Drainage Canal and North Drainage Canal, which were greatly influenced by the development and urbanization of Tianjin. The object of this study was to further interpret the measurement data of PAHs (Qi et al. 2010a) in order to explain the role of organic matter on partitioning of PAHs in view of our previous studies (Qi et al. 2010b). The in situ partitioning of PAHs between the dissolved phase (DP), suspended particulate matter (SPM), pore water (PW), and sediment in the streams of Tianjin was studied. PAHs compo- sitions in sediment as well as in soils by riverbank were investigated to speculate the origins of PAHs in the streams.

\section{Materials and methods}

\section{Sampling streams}

The map of the sampling area and the locations of sampling sites are indicated in Fig. 1. South Drainage Canal, which is $67.5 \mathrm{~km}$, originates from the Xianyanglu wastewater treatment plant (WWTP) and flows into Bohai Bay in the Tanggu area of Tianjin. North Drainage Canal is $33 \mathrm{~km}$, originates from Zhaoguli pump station and merges into Yongding New River. Yongding New River is $62 \mathrm{~km}$ and originates from the downstream of North Canal which flows through Beijing. Many rivers and canals merge into Yongding New River, such as Airport Drainage Canal, Beijing Drainage Canal, Chaobai New River, Ji Canal, Jinzhong River and North Drainage Canal, etc. Yongding New River is one of the flood-discharging channel of Tianjin and acts as an important input path of Yongding River, North Canal, Chaobai New River, and Ji Canal into the Bohai Sea.

There were 16 (Y1 to Y16), seven (N1 to N7), and 11 (S1-S11) sampling sites in Yongding New River, North Drainage Canal, and South Drainage Canal, respectively. Surface water, suspended particulate matters, and pore water samples were collected in June and October of 2007 and January of 2008, respectively. Sediment samples were collected in June of 2007. Four effluent samples from WWTPs or pump station (collecting municipal wastewater and rainwater) including Zhaoguli (ZGL) pump station, Dongjiao (DJ) WWTP, Xianyanglu (XY) WWTP, and Jizhuangzi (JZZ) WWTP (presented by stars in Fig. 1) were collected at the outflow in January of 2008. In addition, nine soil samples by riverbank were collected in June of 2007. They were located in the farmlands near Y2, Y3, Y4, Y5, Y7, N1, N2, N5, and N7 (Fig. 1). 


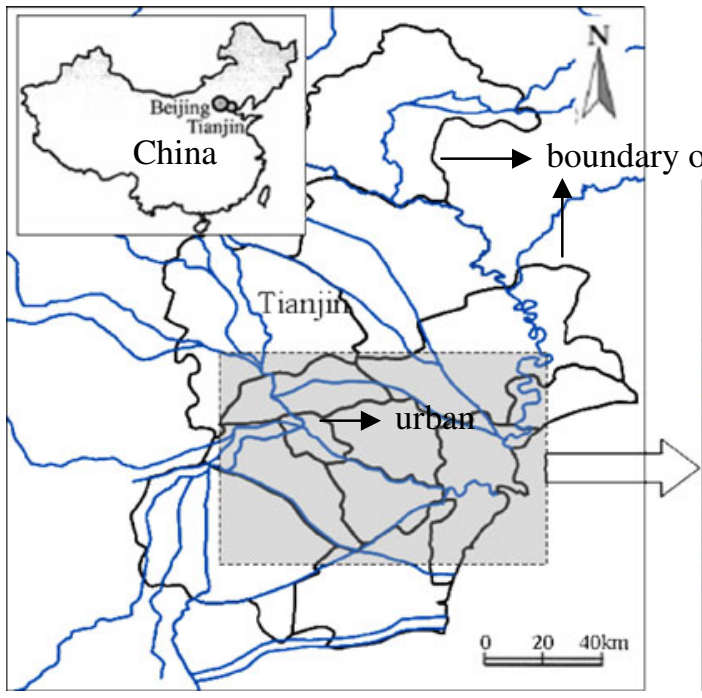

Fig. 1 Map of Tianjin and main streams of the city (left); map of the sampling area and the location of the sampling sites in Yongding New River (Y1-Y16), North Drainage Canal (Northsewer, N1-N7), and South

PAHs and organic matters analysis

Detailed information about sampling, PAHs analysis, total organic carbons and black carbons contents determination, quality assurance, and quality control has been described in our previous study (Qi et al. 2010a, b). Briefly, 16 priority PAHs, i.e., naphthalene (Nap), acenaphthylene (Acy), acenaphthene (Ace), fluorene (Fl), phenanthrene (Phe), anthracene (Ant), fluoranthene (Fluo), pyrene (Pyr), benz $[a]$ anthracene (BaA), chrysene (Chry), benzo[b]fluoranthene $(\mathrm{BbF})$, benzo[k]fluoranthene $(\mathrm{BkF})$, benzo $[a]-$ pyrene (BaP), indeno[1,2,3-cd]pyrene (Ind), dibenz $[a, h]$ anthracene (DBA), benzo[ghi]perylene (BghiP), were determined with GC/MS in all samples. Total organic carbons (TOC) and black carbons contents in sediments were detected with element analyzer (Vario EL III). Briefly, the meshed sediment $(<250 \mu \mathrm{m})$ was treated with $10 \% \mathrm{HCl}$ solution to remove inorganic carbon and dried overnight at $60^{\circ} \mathrm{C}$ before TOC determining. Subsample upon acidification was further oxidized thermally in a muffle furnace

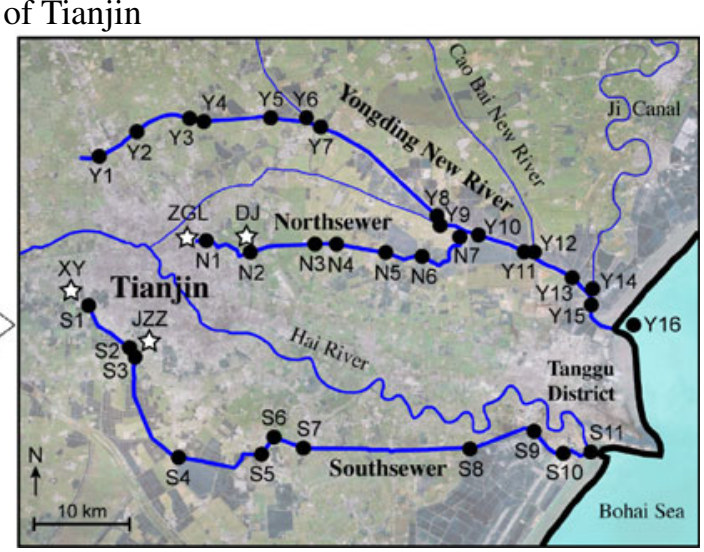

Drainage Canal (Southsewer, S1-S11; right). ZGL Zhaoguli pump station, DJ Dongjiao wastewater treatment plant, $X Y$ Xianyanglu wastewater treatment plant, $J Z Z$ Jizhuangzi wastewater treatment plant

at $375^{\circ} \mathrm{C}$ for $24 \mathrm{~h}$ before being used for $\mathrm{BC}$ determination. Three to $10 \mathrm{mg}$ of sediment was used for TOC and BC analysis. The Geochemical Standard Reference Sample GSS-1 Soil supplied by the National Measurement Science Academy was used as external standard.

Calculation of partition coefficients of PAHs among different phases

To provide insight into phase distribution processes in the three streams of Tianjin, the organic carbon normalized partition coefficients $K_{\mathrm{oc}}$ between SPM and surface water, sediment and PW were computed, respectively. First, the solidwater distribution coefficient, $K_{\mathrm{d}}\left(=C_{\mathrm{SPM}} / C_{\mathrm{DP}}\right.$ or $\left.=C_{\text {sediment }} / C_{\mathrm{PW}}\right)$, was calculated. Then the $K_{\mathrm{oc}}$ values were computed from the $K_{\mathrm{d}}$ values and the TOC data of SPM or sediment. The TOC contents in SPM samples of this study were not measured. In the calculation of $K_{\mathrm{oc}}$ between SPM and DP, the TOC data of SPM cited the average concentration in rivers of Tianjin reported by Shi et al. (2007). It was comparable to the median 
Fig. 2 Correlation of total PAHs contents with TOC and BC contents in the sediments ( $p$ level of significance; $r$ Pearson correlation coefficient)
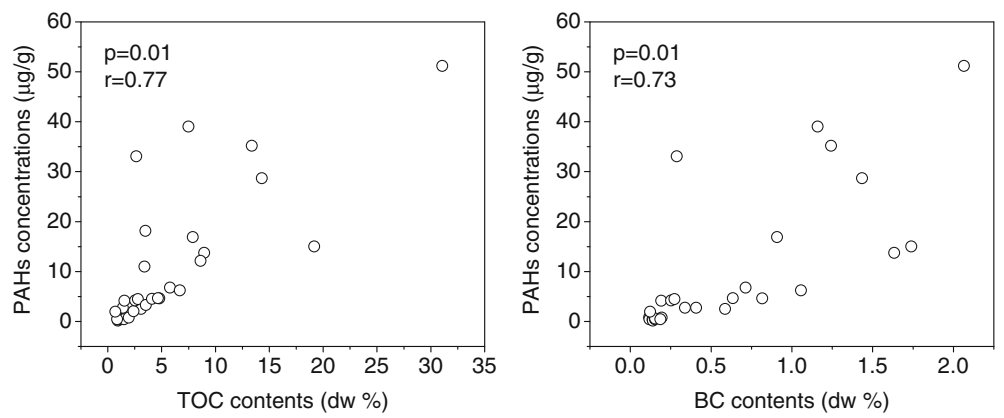

values of TOC (3.24\%) measured in the sediment samples of this study.

\section{Results and discussion}

Partitioning of PAHs among surface water, SPM, PW, and sediment phases

It has been clear that natural organic matter was the most important factors governing the behavior and fate of PAHs in different phases of streams of Tianjin (Shi et al. 2007). As shown in Fig. 2, the contents of PAHs in the sediments showed significant positive relation with both total organic carbon and black carbon contents in the sediments. At level of significance $(p)$ of 0.01 , the correlation coefficients were 0.77 and 0.73 between $\mathrm{PAHs}$ concentrations with TOC and BC contents, respectively.

Furthermore, BC also played an important role in the association of PAHs in the sediments of Yongding New River, North Drainage Canal, and South Drainage Canal (Fig. 2). The weight fractions of $\mathrm{BC}$ in the sediments of our study were $0.12-0.82 \%, 0.19-1.74 \%$, and $0.12-2.07 \%$ for Yongding New River, South Drainage Canal, and North Drainage Canal, respectively (Fig. 3).
The ratios of $\mathrm{BC}$ contents to TOC contents were 10-24.5\%, 9-21.5\%, and 6.6-17.9\%, respectively (Fig. 4). These results are comparable to those reported previously, such as $3-13 \%$ of TOC for the sediments of New England harbors (Gustafsson and Gschwend 1998), 5-39\% of TOC for lake sediments of France (Lim and Cachier 1996), 18.3\% of TOC for marine sediment in Zhuhai (Song et al. 2002). However, they were lower than the result of $33.0 \%$ of TOC for the river sediment in the Pearl River, $41.0 \%$ of TOC for the pond sediment in Guangzhou, China (Song et al. 2002). Cao et al. (2006) reported a detailed organic carbon (OC) and BC aerosols emissions in China. In their study, total emissions were $37.4 \mathrm{Gg}$ OC and 14.4 Gg BC in Tianjin where the three streams of this study are located. That meant BC accounted for $38.5 \%$ of $\mathrm{OC}$ in the aerosols emission in Tianjin. Comparing with this, the BC to TOC ratios in the sediments of this study were about one to two times lower. This suggested the complex input of organic matters into the canals. If we compare the $\mathrm{BC}$ to $\mathrm{TOC}$ ratios among the three studied streams, we could find that the ratios in Yongding New River (10-24.5\%) were higher than those in the two canals (6.6-21.5\%). This proved our hypothesis to some extent as Yongding New River acts as both water resources
Fig. 3 Concentrations of TOC and $\mathrm{BC}$ in the sediment from $Y D R$. Yongding New River, $S D$ $C$. South Drainage Canal, and $N D C$. North Drainage Canal
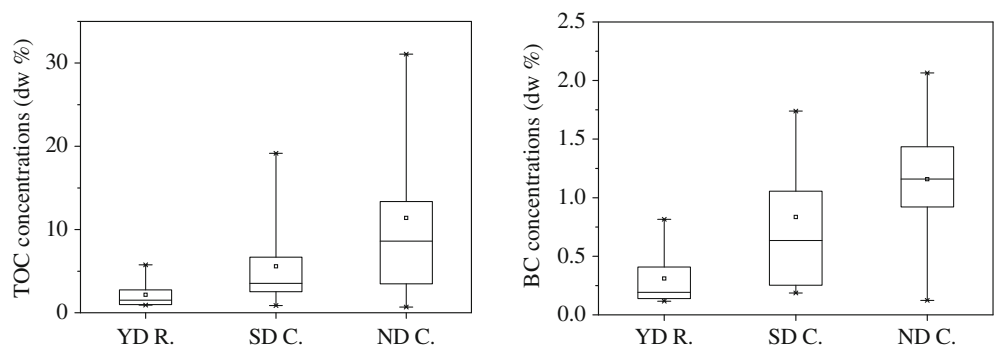


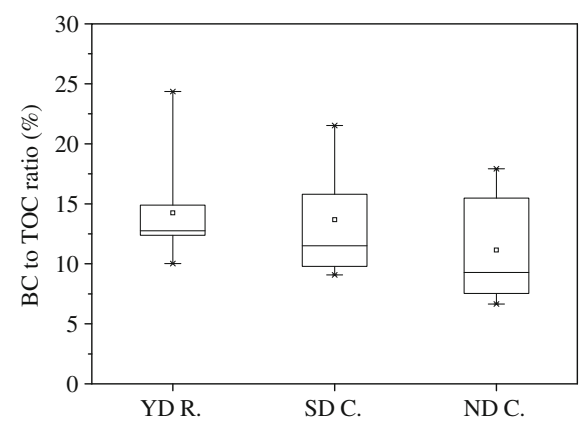

Fig. 4 The ratio of $\mathrm{BC}$ to TOC concentrations in the sediments from $Y D R$. Yongding New River, $S D C$. South Drainage Canal, and $N D C$. North Drainage Canal

for agriculture irrigation and waterway for flood control in wet seasons except receiving wastewater from Tianjin.

$\mathrm{BC}$ as well as kerogen carbon and diagenetically aged material are viewed as comprised of "glassy" organic matter responsible for strong HOC sorption, nonlinear adsorption behavior, and slow mass transfer rates (Rockne et al. 2002; Ran et al. 2007). Assuming the overall sedimentwater distribution coefficient $K_{\mathrm{d}}$ can be apportioned into the terms representing organic carbon absorption and $\mathrm{BC}$ adsorption, Lohmann et al. found that BC was responsible for over $90 \%$ of the total PAH sorption in Boston Harbor sediment and over $80 \%$ in New York Harbor sediment (Lohmann et al. 2005). The positive relation between $\mathrm{BC}$ contents with PAHs concentrations indicated that $\mathrm{BC}$ was an important factor controlling the partitioning of PAHs in the sediments of this study.

The in situ partition of PAHs among different phases was calculated in this study. The calculated partition coefficients between SPM and surface water, sediment and PW, $K_{\mathrm{oc}}$ using measured data versus the predicted $K_{\mathrm{oc}}$ using Lohmann's expressions (Lohmann et al. 2005) were listed in Table 1. As is expected, the measured organic carbon normalized partition coefficients $\log K_{\mathrm{oc} \text {,obs }}$ between SPM and surface water in the three streams were higher than the predicted partition coefficients for all 16 PAHs compounds except DBA. The divergence of $\log K_{\mathrm{oc} \text {,obs }}$ values from such predictions was highest for lower molecular weight PAHs (with two or three rings) in Yongding New River and South Drainage Canal and exceeded $\log K_{\text {oc,pred }}$ by about $0.76-1.32,0.93-1.38 \log$ units, respectively. While for North Drainage Canal, the

Table 1 Comparison of measured organic carbon normalized SPM-DP, sediment-PW partition coefficients (log $\left.K_{\mathrm{oc}, \mathrm{obs}}\right)$ with predicted $\log K_{\mathrm{oc}}$ in Yongding New River, South Drainage Canal and North Drainage Canal

\begin{tabular}{|c|c|c|c|c|c|c|c|}
\hline \multirow[t]{4}{*}{ PAHs } & \multicolumn{6}{|l|}{ Measured } & \multirow{4}{*}{$\begin{array}{l}\text { Predicted } \\
\log K_{\text {oc,pred }}^{\mathrm{a}}\end{array}$} \\
\hline & \multicolumn{3}{|c|}{$\log K_{\mathrm{oc}, \mathrm{obs}}(\mathrm{SPM}$-surface water $)$} & \multicolumn{3}{|c|}{$\log K_{\mathrm{oc}, \mathrm{obs}}($ sediment-PW) } & \\
\hline & Yongding & South & North & Yongding & South & North & \\
\hline & New River & Drainage Canal & Drainage Canal & New River & Drainage Canal & Drainage Canal & \\
\hline Nap & $4.47 \pm 0.72$ & $4.07 \pm 0.88$ & $4.41 \pm 0.46$ & $3.56 \pm 0.67$ & $3.78 \pm 0.42$ & $3.85 \pm 0.19$ & 3.15 \\
\hline Acy & $4.84 \pm 0.53$ & $5.07 \pm 0.54$ & $4.72 \pm 0.44$ & $4.32 \pm 0.52$ & $4.20 \pm 0.69$ & $4.86 \pm 0.26$ & 3.76 \\
\hline Ace & $4.44 \pm 0.60$ & $4.89 \pm 0.55$ & $4.20 \pm 0.50$ & $3.76 \pm 0.62$ & $3.54 \pm 0.55$ & $3.96 \pm 0.23$ & 3.68 \\
\hline $\mathrm{Fl}$ & $4.88 \pm 0.53$ & $5.12 \pm 0.50$ & $4.60 \pm 0.35$ & $4.16 \pm 0.52$ & $4.04 \pm 0.44$ & $4.42 \pm 0.13$ & 3.93 \\
\hline Phe & $5.28 \pm 0.46$ & $5.51 \pm 0.42$ & $5.27 \pm 0.28$ & $4.45 \pm 0.49$ & $4.31 \pm 0.55$ & $5.01 \pm 0.34$ & 4.31 \\
\hline Ant & $5.30 \pm 0.54$ & $5.67 \pm 0.44$ & $5.48 \pm 0.27$ & $4.89 \pm 0.60$ & $5.10 \pm 0.74$ & $5.17 \pm 0.09$ & 4.28 \\
\hline Fluo & $5.58 \pm 0.53$ & $5.79 \pm 0.46$ & $6.05 \pm 0.44$ & $5.26 \pm 0.56$ & $4.82 \pm 0.57$ & $5.59 \pm 0.12$ & 4.94 \\
\hline Pyr & $5.65 \pm 0.55$ & $5.86 \pm 0.45$ & $6.21 \pm 0.26$ & $5.43 \pm 0.58$ & $5.17 \pm 0.49$ & $5.70 \pm 0.11$ & 4.90 \\
\hline $\mathrm{BaA}$ & $5.99 \pm 0.62$ & $6.52 \pm 0.68$ & $6.80 \pm 0.28$ & $5.83 \pm 0.48$ & $5.46 \pm 0.65$ & $5.55 \pm 0.63$ & 5.61 \\
\hline Chry & $5.90 \pm 0.57$ & $6.10 \pm 0.51$ & $6.56 \pm 0.26$ & $5.68 \pm 0.55$ & $5.54 \pm 0.92$ & $5.97 \pm 0.09$ & 5.56 \\
\hline $\mathrm{BbF}$ & $6.22 \pm 0.68$ & $5.91 \pm 0.56$ & $7.05 \pm 0.41$ & $6.87 \pm 0.48$ & $6.17 \pm 0.65$ & $6.45 \pm 0.47$ & 5.51 \\
\hline $\mathrm{BkF}$ & $6.03 \pm 0.67$ & $6.26 \pm 0.77$ & $6.77 \pm 0.38$ & $6.07 \pm 0.53$ & $5.96 \pm 0.58$ & $6.28 \pm 0.48$ & 5.70 \\
\hline $\mathrm{BaP}$ & $6.11 \pm 0.67$ & $6.30 \pm 0.58$ & $7.02 \pm 0.39$ & $6.55 \pm 0.62$ & $6.16 \pm 0.34$ & $6.84 \pm 0.29$ & 5.74 \\
\hline Ind & $6.55 \pm 0.77$ & $6.35 \pm 0.82$ & $7.48 \pm 0.38$ & $6.72 \pm 0.47$ & $6.28 \pm 0.67$ & $6.53 \pm 0.86$ & 6.19 \\
\hline DBA & $5.86 \pm 0.75$ & $5.99 \pm 0.79$ & $6.87 \pm 0.48$ & $4.76 \pm 0.65$ & $5.96 \pm 0.17$ & $6.69 \pm 0.60$ & 6.43 \\
\hline BghiP & $6.35 \pm 0.65$ & $6.28 \pm 0.66$ & $7.08 \pm 0.27$ & $6.72 \pm 0.48$ & $6.43 \pm 0.39$ & $6.48 \pm 0.37$ & 6.19 \\
\hline
\end{tabular}

${ }^{\mathrm{a}} \log K_{\mathrm{oc}, \text { pred }}=0.97 \log K_{\mathrm{ow}}-0.12$; Lohmann et al. (2005); the $\log K_{\mathrm{ow}}$ values refer to Mackay et al. (1992) 
largest discrepancy of $\log K_{\mathrm{oc} \text {,obs }}$ values from predictions was for PAHs compounds of three to six rings except DBA, which was about 0.89-1.54 log units. Also, most of $\log K_{\mathrm{oc} \text {, obs }}$ between sediment and PW in the three streams were also higher than the predicted partition coefficients. This could be explained by the strong and nonlinear sorption of PAHs by carbonaceous geosorbents including BC in the sediment (Mcgroddy and Farrington 1995; Bucheli and Gustafsson 2000; Lohmann et al. 2005; Cornelissen et al. 2005, 2006). In addition, the rather slow release of PAHs after an initial rapid release from sediments collected from Yongding New River, South Drainage Canal, and North Drainage Canal PAHs which we reported previously in the desorption experiment (Qi et al. 2010b) also proved this strong sorption of PAHs by carbonaceous particles in the sediment. So we could conclude that both in situ PAHs measurement data and simulated PAHs desorption process in the lab indicated that strong and nonlinear sorption of PAHs by sorbent such as BC existed in the studied streams.

\section{Sources of PAHs in the streams}

Coal combustion has been identified to be a longterm and prevailing contamination source for sediment in the rivers of Tianjin (Shi et al. 2007). Our previous study reported that coke oven sources and wood combustion also contributed to the PAHs contamination of Yongding New River, South Drainage Canal, and North Drainage Canal (Qi et al. 2010a). As we can expect, wastewater discharges, surface runoff, and air deposition (both dry and wet) were the possible pathways of carbonaceous particles and PAHs entering the steams. Here, we compare the PAHs isomer ratios in effluent samples from WWTPs that discharge into the studied streams, SPM and sediment samples from the streams, and the soil samples by the riverbank that were collected in this study in June of 2007.

Parent PAHs of molecular mass 178 (Ant and Phe), 202 (Fluo and Pyr), 228 (BaA and Chry), and 276 (Ind and BghiP) are commonly used to distinguish between petrogenic sources (leakage of oil or petroleum products) and pyrogenic sources (incomplete combustion of fossil fuel or wood). Yunker et al. (2002) integrated the four isomer ratios, Ant/178, Fluo/202, BaA/228, and Ind/276, from a large number of environmental samples or single sources. For Ant/178, ratios below 0.1 indicate petrogenic origins, while ratios at 0.1 and above have been attributed to pyrogenic origins. For Fluo/202 and Ind/276, ratios below 0.4 and 0.2 , respectively, suggest petrogenic origins while ratios at 0.5 and above indicate fuel combustion. In the case of $\mathrm{BaA} / 228$, ratios below 0.2 have been attributed to petrogenic origins and above 0.35 suggest pyrogenic origins.

Ant/178 against Fluo/202 ratios in samples of this study were plotted in Fig. 5. Ratios of Ant/178 and Fluo/202 in most of the sediment samples and all effluent samples of WWTPs were higher than 0.1 and 0.5 , respectively, suggesting the predominant pyrogenic source for the PAHs. Although
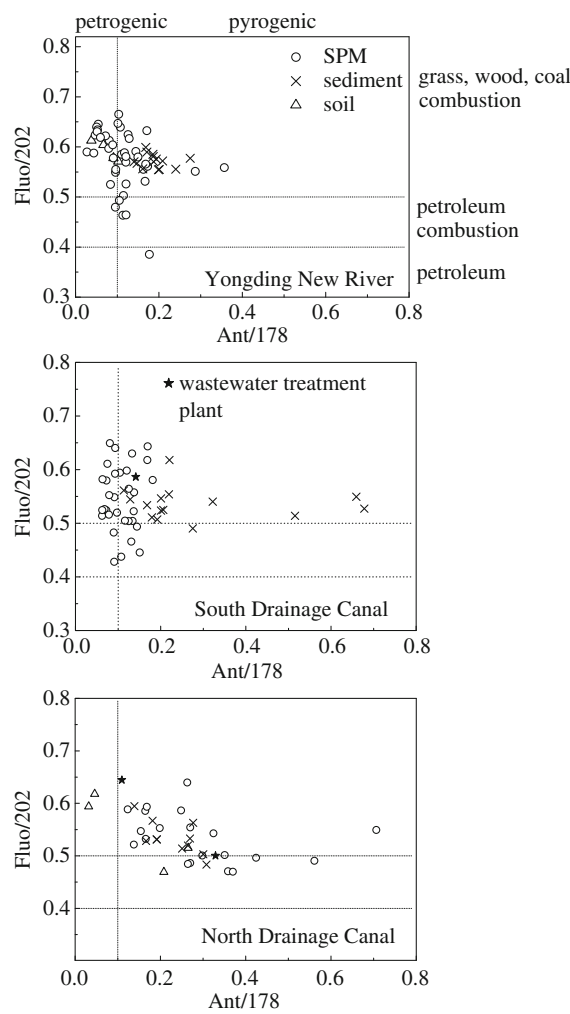

Fig. 5 PAH cross-plots for the ratios of Ant/178 vs. Fluo/202 in SPM, sediment samples from the streams, soil samples from the riverbank, and WWTPs (represented in stars) 
the major PAHs sources to all the sediment samples were similar, detailed characteristics could be identified among the different streams. To be specific, remarkably consistent isomer ratios for PAHs were found in sediments of Yongding New River, indicating the similar sources of the isomer pairs to the different sampling sites (Dickhut et al. 2000). While the cross-plots of isomer ratios in sediments of South Drainage Canal and North Drainage Canal were distributed dispersedly. This might reflect the more complex PAHs input sources to these two drainage canals (Mai et al. 2003).

PAHs sources in surface soil and dustfall has been identified and apportioned (Zuo et al. 2007; $\mathrm{Wu}$ et al. 2005). For soil samples in the urbansuburban zone, $37 \%$ PAHs was from a combined source of coal and petroleum, 26\% was from a combined source of coking and biomass, and 23\% was from incineration (Zuo et al. 2007). For dustfall samples in Tianjin, coal combustion was identified as the main PAHs source (Wu et al. 2005). From Fig. 5 we can see that PAHs source to the soil samples by the riverbank could be identified as the combined source of combustion and petrogenic sources. Comparing with the soil samples by riverbank, PAHs in sediment samples from Yongding New River and Northsewer seemed to be more associated with coal/grass/wood combustion.

Further comparison between PAHs compositions in sediments and soils were carried out by

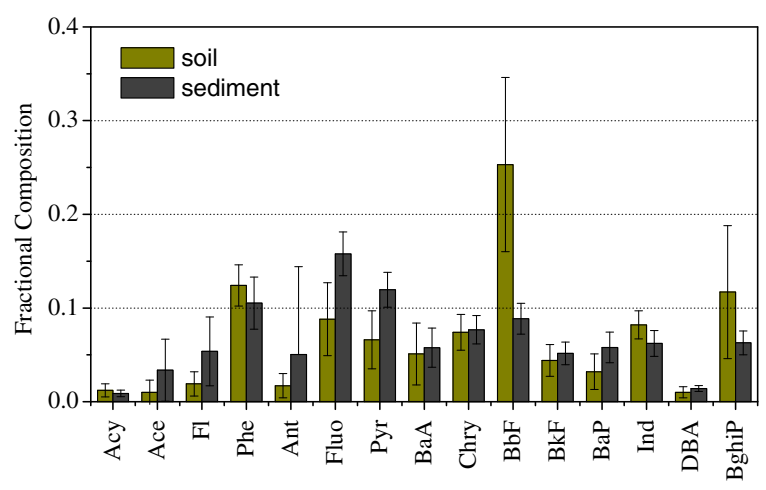

Fig. 6 Fractional composition of PAHs in sediments from Yongding New River and in soils by the riverbank collected in June, 2007 comparing the PAHs profiles which were generated using the same procedure described in the previous literatures (Li et al. 2003; Bzdusek and Christensen 2004). In brief, the concentrations of PAHs were normalized to that of BaP. Then, the fractions were calculated. The fractional compositions of individual PAHs in sediments and soils are presented in Fig. 6. Comparing with the sediments, PAHs in soils was low in Fluo, Pyr, and $\mathrm{BaP}$, but enriched with $\mathrm{BbF}$, BghiP, and Ind, which indicated more contribution of coking and vehicular sources to PAHs in soils than to those in sediments (Bzdusek and Christensen 2004; Zuo et al. 2007).

Compared with sediment, SPM analysis could only explain a short-term contamination source especially in wet season (Shi et al. 2007). As we can see from Fig. 5, although a combined source from grass/wood/coal combustion and petrogenic source could be identified in SPM, the cross-plots of isomer ratios in SPM samples of Yongding New River were distributed more dispersedly than in sediments.

Generally, PAHs in the sediment of Yongding New River, South Drainage Canal, and North Drainage Canal, effluent samples of WWTPs, and soil samples by the riverbank had similar main sources although the two drainage canals had more complex PAHs input. Comparing with the soil samples by the riverbank, PAHs in sediment samples from Yongding New River and Northsewer seemed to be more associated with coal/grass/wood combustion.

\section{Conclusions}

Combining the above analysis about partitioning and sources of PAHs in the studied streams, we could see carbonaceous particles (including black carbon) is an important factor influencing the partitioning of PAHs among different phases in the streams. Coal and petroleum combustion was the main PAHs source in the streams, WWTPs, and soil by the riverbank. The transportation and transformation of both carbonaceous particles and PAHs during wastewater treatment process, surface runoff, etc, should be studied further in 
order to make decisions on PAHs controlling measures.

Acknowledgements This work was supported by the National Basic Research Program of China (Grant 2007CB407301), Natural Science Foundation for the Youth (40701165), and Sino-Swiss Science and Technology Cooperation for Joint Research Projects (GJHZ0908).

\section{References}

Abu, A., \& Steve, S. (2005). Assessing sequestration of selected polycyclic aromatic hydrocarbons by use of adsorption modeling and temperature-programmed desorption. Environmental Science \& Technology, 39, 7585-7591.

Allen-King, M. R., Grathwohl, P., \& Ball P. W. (2002). New modeling paradigms for the sorption of hydrophobic organic chemicals to heterogeneous carbonaceous matter in soils, sediments, and rocks. Advances in Water Resources, 25, 985-1016.

Bucheli, D. T., \& Gustafsson, Ö. (2000). Quantification of the soot-water distribution coefficient of PAHs provides mechanisms basis for enhanced sorption observations. Environmental Science \& Technology, 34, 5144-5151.

Bzdusek, A. P., \& Christensen, R. E. (2004). Source apportionment of sediment PAHs in lake Calumet, Chicago: Application of factor analysis with nonnegative constraints. Environmental Science \& Technology, 38, 97-103.

Cao, G. L., Zhang, X. Y., \& Zheng, F. C. (2006). Inventory of black carbon and organic carbon emissions from China. Atmospheric Environment, 40, 6516-6527.

Cornelissen, G., Breedveld, D. G., Kalaitzidis, S., Christanis, K., Kibsgaard, A., \& Oen, M. P. A. (2006). Strong sorption of native PAHs to pyrogenic and unburned carbonaceous geosorbents in sediments. Environmental Science \& Technology, 40, 1197-1203.

Cornelissen, G., Gustafsson, Ö., Bucheli, D. T., Jonker, T. O. M., Koelmans, A. A., \& Noort, C. M. V. P. (2005). Extensive sorption of organic compounds to black carbon, coal, and kerogen in sediments and soils: Mechanisms and consequences for distribution, bioaccumulation, and biodegradation. Environmental Science \& Technology, 39, 6881-6895.

Dickhut, M. R., Canuel, A. E., Gustafson, E. K., Liu, K., Arzayus, M. K., Walker, E. S., et al. (2000). Automotive sources of carcinogenic polycyclic aromatic hydrocarbons associated with particulate matter in the Chesapeake Bay region. Environmental Science \& Technology, 34, 4635-4640.

Gustafsson, Ö., \& Gschwend, P. M. (1998). The flux of black carbon to surface sediments on the New England continental shelf. Geochimica et Cosmochimica Acta, 62, 465-472.

Gustafsson, Ö., Haghseta, F., Chan, C., Macfarlane, J., \& Gschwend, M. P. (1997). Quantification of the dilute sedimentary soot phase: Implications for PAH speciation and bioavailability. Environmental Science \& Technology, 31, 203-209.

Li, A., Jang, K. J., \& Scheff, A. P. (2003). Application of EPA CMB8.2 model for source apportionment of sediment PAHs in Lake Calumet, Chicago. Environmental Science \& Technology, 37, 2958-2965.

Lim, B., \& Cachier, H. (1996). Determination of black carbon by chemical oxidation and thermal threatment in recent marine and lake sediments and CretaceousTertiary clays. Chemical Geology, 131, 143-154.

Lohmann, R., Macfarlane, K J., \& Gschwend, M. P. (2005). Importance of black carbon to sorption of native PAHs, PCBs, and PCDDs in Boston and New York harbor sediments. Environmental Science \& Technology, 39, 141-148.

Luthy, R. G., Aiken, R. G., Brusseau, L. M., Cunningham, D. S., Gschwend, M. P., \& Pignatello, J. J. (1997). Sequestration of hydrophobic organic contaminants by geosorbents. Environmental Science \& Technology, 31, 3341-3347.

Mackay, D., Shiu, W. Y., \& Ma, K. C. (1992). Illustrated Handbook of Physical-Chemical Properties and Environmental Fate for Organic Chemicals: Polynuclear Aromatic Hydrocarbons, Polychlorinated Dioxins, and Dibenzofurans, vol. 2. Lewis Publishers, Boca Raton, pp. 62-238.

Mai, B. X., Qi, S. H., Zeng, E. Y., Yang, Q. S., Zhang, G., $\mathrm{Fu}$, J. M., et al. (2003). Distribution of polycyclic aromatic hydrocarbons in the coastal region off Macao, China: Assessment of input sources and transport pathways using compositional analysis. Environmental Science \& Technology, 37, 4855-4863.

Mcgroddy, S. E., \& Farrington, W. J. (1995). Sediment porewater partitioning of polycyclic aromatic hydrocarbons in three cores from Boston Harbor, Massachusetts. Environmental Science \& Technology, 29, 1542-1550.

Nam, K., Chung, N., \& Alexander, M. (1998). Relationship between organic matter content of soil and the sequestration of Phenanthrene. Environmental Science \& Technology, 32, 3785-3788.

Qi, W. X., Liu, H. J., Qu, J. H., Hu, C. Z., Lan, H. C., Berg, M., et al. (2010a). Polycyclic aromatic hydrocarbons in effluents from wastewater treatment plants and receiving streams in Tianjin, China. Environmental Monitoring and Assessment. doi:10.1007/S10661-010-1648-4.

Qi, W. X., Liu, H. J., Qu, J. H., Ren, H. M., \& Xu, W. (2010b). PAH desorption from sediments with different contents of organic carbon from wastewater receiving rivers. Environmental Science and Pollution Research. doi:10.1007/s11356-010-0379-y.

Ran, Y., Sun, K., Yang, Y., Xing, B. S., \& Zeng, E. (2007). Strong sorption of phenanthrene by condensed organic matter in soils and sediments. Environmental Science \& Technology, 41, 3952-3958.

Rockne, K. J., Shor, M. L., Young, Y. L., Taghon, L. G., \& Kosson, S. D. (2002). Distributed sequestration and release of PAHs in weathered sediment: The role of sediment structure and organic carbon 
properties. Environmental Science \& Technology, 36, 2636- 2644.

Shao, J., Shi, G. Q., Jin, X. L., Song, M. Y., Shi, J. B., \& Jiang, G. B. (2005). Preliminary survey of estrogenic activity in part of waters in Haihe River, Tianjin. Chinese Science Bulletin, 50, 2565-2570.

Shi, Z., Tao, S., Pan, B., Fan, W., He, X. C., Zuo, Q., et al. (2005). Contamination of rivers in Tianjin, China by polycyclic aromatic hydrocarbons. Environmental Pollution, 134, 97-111.

Shi, Z., Tao, S., Pan, B., Liu, W. X., \& Shen, W. R. (2007). Partitioning and source diagnostics of polycyclic aromatic hydrocarbons in rivers in Tianjin, China. Environmental Pollution, 146, 492-500.

Shor, L. M., Rockne, K. J., Taghon, G. L., Yong, L. Y., \& Kosson, D. S. (2003). Desorption kinetics for field-aged polycyclic aromatic hydrocarbons from sediments. Environmental Science \& Technology, 37, 1535-1544.

Song, J. Z., Peng, P. A., \& Huang, W. L. (2002). Black carbon and kerogen in soils and sediments. 1. Quantification and characterization. Environmental Science \& Technology, 36, 3960-3967.
Weber, W. J., McGinley, P. M. J., \& Katz, L. E. (1992). A distributed reactivity model for sorption by soils and sediments. 1. Conceptual basis and equilibrium assessments. Environmental Science \& Technology, 26, 1955-1962.

Wu, S. P., Tao, S., Xu, F. L., Dawson, R., Lan, T., Li, B. G., et al. (2005). Polycyclic aromatic hydrocarbons in dustfall in Tianjin, China. Science of the Total Environmental, 345, 115-126.

Yang, R. Q., Lv, A. H., Shi, J. B., \& Jiang, G. B. (2005). The levels and distribution of organochlorine pesticides (OCPs) in sediments from the Haihe River, China. Chemosphere, 61, 347-354.

Yunker, M. B., Macdonald, R. W., Vingarzan, R., Mitchell, R. H., Goyette, D., \& Sylvestre, S. (2002). PAHs in the Fraser River basin: A critical appraisal of PAH ratios as indicators of PAH source and composition. Organic Geochemistry, 33, 489-515.

Zuo, Q., Duan, Y. H., Yang, Y., Wang, X. J., \& Tao, S. (2007). Source apportionment of polycyclic aromatic hydrocarbons in surface soil in Tianjin, China. Environmental Pollution, 147, 303310. 